\title{
Inhibition of xenograft human glioma tumor growth by lentivirus-mediated gene transfer of alphastatin
}

\author{
HONGMIN CHE ${ }^{1,3^{*}}$, JIANRONG SONG ${ }^{2 *}$, SHIWEN GUO $^{3 *}$, WEIWEN WANG $^{1}$ and GUODONG GAO ${ }^{1}$ \\ ${ }^{1}$ Department of Neurosurgery, The Second Affiliated Hospital, the Fourth Military Medical University, Xi'an 710038; \\ ${ }^{2}$ Department of Neurosurgery, Baoji Municipal Central Hospital, Baoji, Shannxi 721008; ${ }^{3}$ Department of Neurosurgery, \\ The First Affiliated Hospital, Medical School of Xi'an Jiaotong University, Xi'an 710061, P.R. China
}

Received October 8, 2012; Accepted November 9, 2012

DOI: $10.3892 /$ or.2012.2187

\begin{abstract}
Angiogenesis is crucial for the development and metastasis of human brain glioma. Based on our previous successful construction of a lentivirus-mediated alphastatin (an endogenous angiogenesis inhibitor) gene transfer system and our findings that alphastatin exhibited potent inhibitory effects on the migration and differentiation of human umbilical vein endothelial cell lines (HUVECs) induced by vascular endothelial growth factor (VEGF) or basic fibroblast growth factor (bFGF) in vitro, here, we investigated the effect of using lentiviral vectors to overexpress alphastatin in human glioma cells to show whether sustained long-term expression of alphastatin diminishes tumor growth in a xenograft glioma model. We found that the transduced glioma cells sustainedly secreted alphastatin, which did not affect the proliferative ability of the glioma cells. Furthermore, tumor xenografts treated with the recombinant lentivirus were significantly smaller compared to the control xenografts and vascularity within the treated tumors was evidently decreased. Our data suggest that stable expression of alphastatin inhibits human glioma growth by inhibiting angiogenesis, with a probable mechanism of suppressing the turnover of VE-cadherin membrane molecules.
\end{abstract}

\section{Introduction}

Malignant gliomas are among the most extensively vascularized human tumors $(1,2)$, which is further supported by the identification of tumor blood vessel density as an independent prognostic parameter for human astroglial tumors (3). The prognosis of malignant gliomas is still dismal despite aggres-

Correspondence to: Professor Guodong Gao, Department of Neurosurgery, The Second Affiliated Hospital, The Fourth Military Medical University, Xi'an 710038, P.R. China

E-mail: nesurgery@yahoo.com.cn

*Contributed equally

Key words: alphastatin, antiangiogenesis, gene transfer, glioma, lentivirus sive treatment attempts. Thus, alternative therapy strategies are needed. Since malignant gliomas are characterized by extensive vascularization and their proliferation is hallmarked by a distinct proliferative vascular component (3), it seems to be a logical consequence to apply antiangiogenic treatment strategies to malignant gliomas. Recently, a large, randomized phase II trail of bevacizumab, pan-VEGFR inhibitor cediranib and other angiogenesis inhibitors was completed $(4,5)$. Preliminary results confirmed the safety of these agents and showed a significant increase in the rate of progress-free survival for patients with malignant gliomas.

There are several angiogenesis inhibitors in the body, which help to suppress pathologic angiogenesis (6-8). Alphastatin, an endogenous angiogenesis inhibitor, is a 24-amino acid peptide derived from the amino terminus of the $\alpha$ chain of human fibrinogen, and has potent antiangiogenic properties in vitro and in tumor models (9-11). In our previous detailed in vitro and in vivo study of angiogenesis inhibition, we utilized a lentivirus-mediated gene transfer system that allows local sustained long-term expression of alphastatin (11) and established models for the prevention of human glioma tumorigenesis. In this study, the recombinant alphastatin lentiviruses were able to stably infect human umbilical vein endothelial cell lines (HUVECs), and exhibited potent inhibitory effects on HUVEC migration and differentiation induced by vascular endothelial growth factor (VEGF) or basic fibroblast growth factor (bFGF). Notably, our data also showed that the stable expression of alphastatin in HUVECs evidently inhibited human glioma tumorigenicity by inhibiting angiogenesis. Furthermore, according to alterations in protein expression during HUVEC tube formation induced by the activation of mitogen-activated protein kinase (MAPK) signaling, we determined that alphastatin inhibited VEGF- or bFGF-induced angiogenesis by the blocking JNK and ERK phosphorylation pathway (11).

To assess the antitumor effects of secreted protein alphastatin and to extend these observations, in the present study, we chose to establish a treatment model of human glioma to assess whether alphastatin could be secreted in human glioma cells transduced by an alphastatin gene delivery system, and simultaneously evaluated the inhibition efficacy of tumor growth following treatment with the secreted protein alphastatin, in order to identify the antitumor mechanism of alphastatin. We 
report here that the lentivirus-mediated gene delivery system of alphastatin is an effective method for the treatment of human malignant glioma of the brain.

\section{Materials and methods}

Cells and reagents. HUVECs, and human glioma cell lines SHG44 and U87 were purchased from Keygen (Yuhuatai, Nanjing, China). Cells were maintained in DMEM supplemented with $10 \%$ FCS, $1 \%$ penicillin and $1 \%$ streptomycin, and were grown at $37^{\circ} \mathrm{C}$ in a humidified incubator with a gas phase of $5 \% \mathrm{CO}_{2}$. Recombinant human VEGF and bFGF were acquired from PeproTech EC (London, UK). Restriction enzymes MluI and EcoRI were purchased from New England Biolabs (Beverly, MA, USA).

Lentiviral vector production and transduction. Construction of the recombinant lentivirus with alphastatin was performed as previously described $(11,12)$. A four-plasmid-based lentiviral expression system was used in our experiment. Lentiviral shuttle plasmid pWPXL-MOD was a kind gift from the University of California, San Diego. Here, SpNT4 stands for the fusion gene containing the human Neurotrophin-4 signal peptide and pro-region. Briefly, to prepare pseudotyped lentiviral vectors, lent-SpNT4-Al, $20 \mu \mathrm{g}$ pWPXL/SpNT4-Al, $12 \mu \mathrm{g}$ pMDLG/pRRE, $10 \mu \mathrm{g}$ pRSV/REV and $10 \mu \mathrm{g}$ pMD2.G were co-transfected into $293 \mathrm{~T}$ cells, which were then cultured in 10-cm dishes with Lipofectamine 2000 (Invitrogen, USA). The lentiviral vector titers were estimated by flow cytometric analyses [fluorescence-activated cell sorting (FACS)] as described previously (13). SHG44 and U87 cells were transduced with Lent-GFP and Lent-SpNT4-Al at the multiplicity of infection of 5-10 in the presence of $6 \mathrm{mg} / \mathrm{ml}$ polybrene (Sigma-Aldrich, St. Louis, MO, USA) for $72 \mathrm{~h}$. SHG44-GFP (SHG44-Null), SHG44-SpNT4-Al-GFP (SHG44-Al), U87-GFP (U87-Null) and U87-SpNT4-Al-GFP (U87-Al), four types of tranduced cells were harvested.

Determination of the expression of secreted protein alphastatin. Based on the identification of secreted protein alphastatin from HUVECs carrying the alphastatin gene as described previously (11), we assessed whether protein alphastatin was secreted from SHG44 and U87 cells carrying the alphastatin gene in conditioned media using a HUVEC migration assay. HUVEC migration is inhibited when alphastatin is secreted in media. The cell migration assay was adapted from Malinda et al (14) and involves the use of a 24-well microchemotaxis chamber (AM; Neuro Probe, Gaithersburg, MD, USA) with $8-\mu \mathrm{m}$ pore size polycarbonate membranes (Neuro Probe). SHG44, U87, SHG44-GFP, U87-GFP, SHG44-A1 and U87 cells were, respectively, cultured in the lower chamber for another $24 \mathrm{~h}$ as subconfluent monolayers in DMEM (containing 1\% FCS), and HUVEC cell suspension $\left(1 \times 10^{5}\right.$ cells $\left./ \mathrm{ml}\right)$ was then added to the upper chambers and incubated at $37^{\circ} \mathrm{C}$ for $8 \mathrm{~h}$ with VEGF or bFGF alone (10 $\mathrm{ng} / \mathrm{ml})$. Migrating cells adhering to the undersurface of the membrane were fixed with $4 \%$ paraformaldehyde and stained with hematoxylin and eosin. The migrating cells were then counted using an optical microscope at $\mathrm{x} 20$ magnification.
Proliferation assay. The MTT assay was performed as previously described to measure the effects of secreted protein alphastatin on the in vitro growth of SHG44 and U87 cells (15). Briefly, SHG44, U87, SHG44-GFP, U87-GFP, SHG44-Al and U87-Al cells were, respectively, seeded into 96-well plates at a density of $3 \times 10^{4}$ cells $/ \mathrm{ml}$ in DMEM for $24,48,72$ and $96 \mathrm{~h}$. At each time point, a quarter volume of MTT solution $(2 \mathrm{mg}$ MTT $/ \mathrm{ml}$ in PBS) was added to each well, and the plates were then incubated for $4 \mathrm{~h}$ at $37^{\circ} \mathrm{C}$. The medium was aspirated and the formazan crystals were dissolved in $150 \mu 1$ of DMSO buffered at $\mathrm{pH} 10.5$. The absorbance was finally read at $590 \mathrm{~nm}$ using a Dynex ELISA plate reader (Ashford, Middlesex, UK).

Immunofluorescence. The surface expression and localization pattern of adherens junction proteins was assessed by immunocytochemistry in VEGF- or bFGF-induced endothelial tube formation as previously described (16). HUVECs $\left(2 \times 10^{5}\right.$ cells $\left./ \mathrm{ml}\right)$ were incubated for $2 \mathrm{~h}$ in $24-w e l l$ plates coated with $250 \mu \mathrm{l} /$ well GFR Matrigel, either with or without $20 \mathrm{ng} /$ $\mathrm{ml}$ bFGF or VEGF, in conditioned media that were collected from SHG44-Al or U87-Al cells, each of which was cultured until subconfluence in DMEM media for $24 \mathrm{~h}$. The medium was then replaced with DMEM containing 1\% FCS for a further $24 \mathrm{~h}$. Cells were then washed and fixed with $4 \%(\mathrm{w} / \mathrm{v})$ paraformaldehyde at room temperature for $10 \mathrm{~min}$ and then permeabilized with $0.5 \%(\mathrm{v} / \mathrm{v})$ Triton and blocked with $5 \%$ (w/v) BSA in PBS for $30 \mathrm{~min}$ at room temperature. They were then incubated with a monoclonal anti-VE-cadherin antibody (1:100) overnight at $4^{\circ} \mathrm{C}$. Cells were then washed before incubation with FITC-conjugated goat anti-mouse $\operatorname{IgG}(1: 1,000)$ for $2 \mathrm{~h}$ at $37^{\circ} \mathrm{C}$. Finally, cells were washed again before being overlaid with PBS and analyzed using a fluorescence microscope.

Western blot analysis. HUVECs were treated as described in the Immunofluorescence section. For each phase during tube formation HUVECs were then washed twice with ice-cold PBS and lysed in lysis buffer [50 mM Tris-HCl (pH 7.9), $5 \mathrm{mM}$ EDTA, $0.1 \%$ SDS, $10 \%$ glycerol, $0.2 \%$ Triton X-100, $5 \mu \mathrm{g} / \mathrm{ml}$ aprotinin, $1 \mathrm{mM}$ PMSF and one protease inhibitor cocktail tablet]. Protein concentrations were determined using a BCA kit (Pierce, Rockford, IL, USA). Each protein lysate (30 $\mu \mathrm{g})$ was separated on SDS-PAGE gels and then transferred onto a polyvinylidene difluoride membrane (Millipore, Billerica, MA, USA). The blots were incubated overnight at $4^{\circ} \mathrm{C}$ with primary antibodies to VE-cadherin and $\beta$-actin, followed by a 1-h incubation with horseradish peroxidase-conjugated secondary antibodies. Proteins were visualized using an enhanced chemiluminescence detection system (Amersham Life Science, Little Chalfont, UK).

Tumor growth inhibition. All animal experiments were approved by the Institutional Animal Care and Use Committee of The Fourth Military Medical University. All experiments were performed on 6-week-old Balb/c mice weighing $20 \mathrm{~g}$ $(\mathrm{n}=13)$ purchased from Jackson Laboratory (Bar Harbor, ME, USA). Animals were anesthetized with an intraperitoneal injection of $10 \%$ chloral hydrate before experiments. Then, $2 \times 10^{6}$ cells $/ \mathrm{ml}$ (in $100 \mu \mathrm{l}$ medium) of viable SHG44 or U87 cells were respectively implanted subcutaneously. Three days after the tumor cells were implanted subcutaneously in the 
A Transfer vector (pWPXL-Alphastatin)

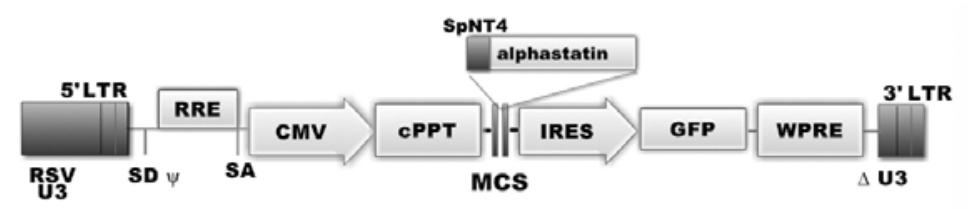

Packing construct (pMDIg-pRRE pRsv-RRE)

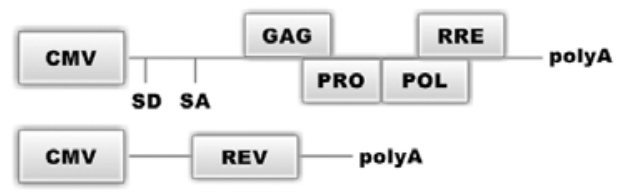

Env-coding plasmid (pMI)2.G)

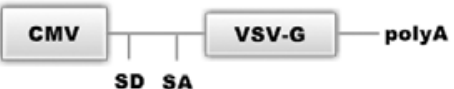

B
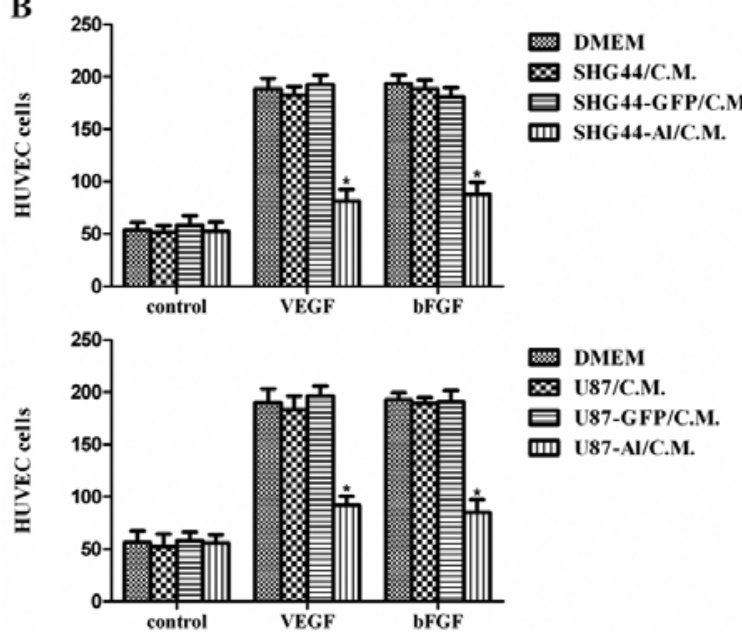

Determination of secreted protein alphastatin

Figure 1. Illustration of the construction and determination of alphastatin expression. (A) Self-inactivating lentiviral vectors: The human neurotrophin-4 signal peptide and pro-region fusion sequences (SpNT4) were cloned into lentiviral transfer vector plasmid pWPXL/GFP, to construct pWPXL-SpNT4-Al. Recombinant lentiviral vectors were produced by cotransfection of the envelope plasmid pMD2.G, packaging plasmid pMDlg-RRE and pRsv-RRE, and transfer vector plasmid LTR, long terminal repeat; RSV U3, U3 region from Rous sarcoma virus; $\psi$, packaging signal; SD, splice donor; SA, splice acceptor; RRE, Rev response element; CMV, cytomegalovirus promoter; MCS, multiple cloning site; IRES, internal ribosome entry site; GFP, green fluorescent protein marker gene; $\triangle \mathrm{U} 3$, self-inactivating deletion in U3 region; polyA, polyadenylation signal; VSV-G, vesicular stomatitis virus G protein envelope. (B) HUVEC migration assay was performed in response to medium or conditioned medium containing or not containing (control) $10 \mathrm{ng} / \mathrm{ml}$ VEGF or bFGF, to confirm that the SHG44-Al (upper panel) and U87-Al cells (lower panel) expressed biologically active alphastatin. All data shown are means \pm SEM. ${ }^{*} \mathrm{P}<0.002$ compared with the respective VEGF or bFGF group.

mice, recombinant lentNT4/Al (lentivirus-SpNT4-alphastatin) was injected intratumorally twice daily, for two days, with $20 \mu 13.4 \times 10^{8} \mathrm{TU} / \mathrm{ml}$ virus. Tumor volumes were measured daily using calipers (17), along with body weight and the state of well-being.

Immunohistochemical analysis. Mice were sacrificed after 16 days. The tumor tissues were excised, divided in half and fixed overnight in either $10 \%$ neutral-buffered formalin or a zinc-based fixative (18), before being embedded in paraffin wax and sectioned. Formalin-fixed tissue sections were subsequently stained with anti-CD31, periodic acid-Schiff (PAS) and hematoxylin to assess microvessel density (MVD). The average vessel count within three selected fields was then scanned at increased magnification (x20), and MVD was expressed as the mean percentage of vessel areas/field from three highly vascularized areas.

Statistical analysis. The data were expressed as the means \pm SEM and representative data from one of the three replicate experiments are shown. The differences between the groups were determined using one-way ANOVA followed by the Student's t-test. A P-value of $<0.05$ was considered to indicate a statistically significant difference.

\section{Results}

Expression of alphastatin in human glioma cells. The recombinant lentivirus vectors for long-term expression of alphastatin were constructed (Fig. 1A). We examined this gene delivery system in SHG44 and U87 human glioma cell lines. Subsequently, SHG44 or U87 cells that were transduced with recombinant lentiviral vectors showed both nuclear and cytoplasmic expression of GFP. Typically at a multiplicity of infection of 5-10, >96\% of lentivirally transduced SHG44 cells and $>98 \%$ of U87 cells are achieved. To confirm that SHG44-Al and U87-Al, but not SHG44-Nul 1 and U87-Null cells, expressed biologically active alphastatin, we next examined the effect of alphastatin expression in an in vitro HUVEC migration assay, in which SHG44-Al and U87-Al cell conditioned media resulted in significant inhibition of endothelial cell migration, whereas conditioned media of SHG44-Null and U87-Null cells did not inhibit endothelial cell migration (Fig. 1B). Based on these data, and combined with previous early-stage results (11), we concluded that the lentiviral vector efficiently transduced alphastatin into the SHG44 and U87 cells, and the SHG44-Al and U87-Al cells secreted active alphastatin.

Effects of alphastatin on the growth of SHG44 and U87 cells. We previously reported that secreted peptide alphastatin inhibited angiogenesis by inhibiting HUVEC migration and tube formation. We further sought to determine whether alphastatin also inhibits the growth ability of human glioma cells following treatment. To evaluate the effects of alphastatin transduction and expression on the growth of SHG44 and U87 cells in vitro, the relative growth rates of SHG44-GFP, U87-GFP, SHG44-Al and U87-A1, and parental SHG44 and U87 cells were compared using MTT methods. As shown in Fig. 2, there was no significant difference between the growth rates of SHG44, SHG44-GFP and SHG44-Al cells, suggesting that neither the lentivirus transduction procedure nor the overexpression of either GFP or alphastatin affected the intrinsic rate of cellular proliferation in these cells. Furthermore, in 

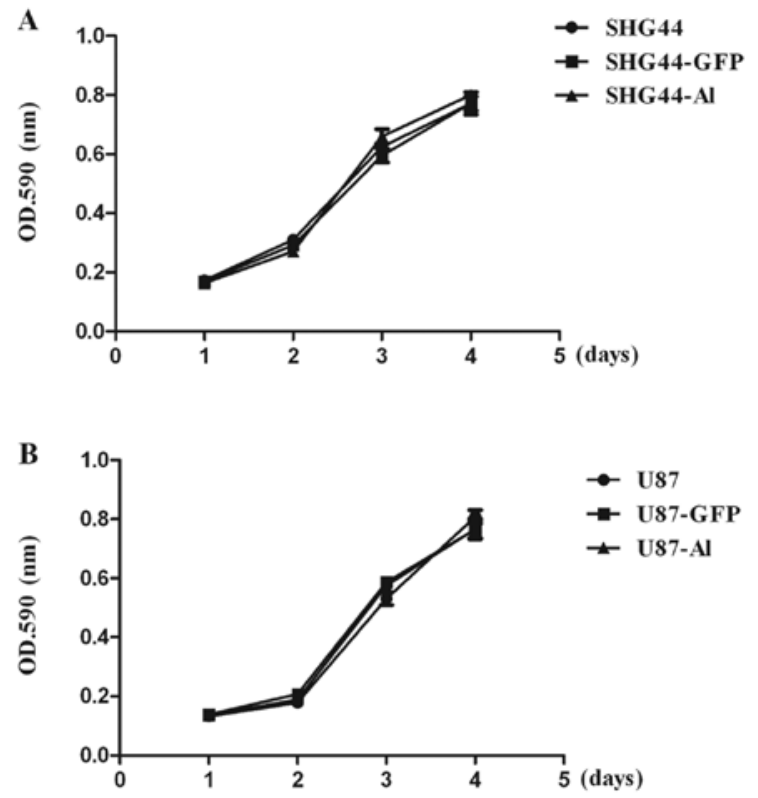

Figure 2. Effect of alphastatin on the growth of (A) SHG44 and (B) U87 cells. Growth rate of SHG44, SHG44-GFP, SHG44-Al U87, U87-GFP and U87 cells was measured by MTT assay. In vitro growth characteristics were similar, respectively, in A and B.

contrast, these data confirmed that secreted protein alphastatin did not effect the growth of SHG44 and U87 cells.

Effects of alphastatin on VE-cadherin. Since VE-cadherin is crucial for controlling the state of adherens junctions, which in turn regulate endothelial cell-cell adhesion, cell motility, morphogenesis and intracellular signaling pathways, this molecule has many clinical implications. To gain insight into one possible molecular mechanism involved in the inhibition of angiogenesis by alphastatin, we sought to determine whether alphastatin influences the expression and distribution of VE-cadherin during HUVEC tube formation. Immunofluorescence analysis showed that VE-cadherin was localized along areas of cell-cell contact. However, 1-2 $\mathrm{h}$ after stimulation by VEGF or bFGF, the VE-cadherin fluorescence was greatly reduced, and even disappeared from most cell-cell contact areas. Whereas, when cells were treated with SHG44-Al or U87-Al conditioned media prior to stimulation with VEGF or bFGF, VE-cadherin maintained localization along areas of cell-cell contact (Fig. 3A). Furthermore, we measured the total amount of VE-cadherin during HUVEC tube formation using western blot analysis and found no significant changes in the levels of total VE-cadherin protein (Fig. 3B). These findings suggest that alphastatin inhibits the decrease in VE-cadherin induced by VEGF or bFGF on the surface of HUVECs without any changes in the total protein of VE-cadherin.

Effects of alphastatin on tumor growth. We examined the inhibitory effect of secreted protein alphastatin on tumor growth in vivo. SHG44 or U87 cells were subcutaneously implanted alone in mice. In all mice, SHG44 tumors grew to a volume between 62 and $1,644 \mathrm{~mm}^{3}$, and U87 tumors grew to a volume between 63 and $1,904 \mathrm{~mm}^{3}$ after 16 days of implantation. However, SHG44 tumors treated with lentNT4/
Al showed a significantly reduced growth rate, reaching a final tumor volume of only $734 \pm 79 \mathrm{~mm}^{3}$ after 16 days $(\mathrm{P}<0.018$; Fig. 4A). The growth rate of U87 tumors was also significantly reduced, reaching a final volume of only $827 \pm 92 \mathrm{~mm}^{3}$ $(\mathrm{P}<0.022$; Fig. 4B). Similar results were obtained in two repeated experiments. Alphastatin was found to be well tolerated by the animals, and had no significant effect on body weight or general well-being (animals were not lethargic, and intermittent hunching, tremors, or disturbed breathing patterns were not observed). These data suggest that secreted protein alphastatin effectively suppresses tumor growth in an established mouse tumor model.

Effects of alphastatin on tumor histology. Histologic analysis revealed a difference in MVD between the two implanted xenograft tumor groups. MVD was determined by the examination of CD31-stained sections at those sites with the highest number of capillaries and small venules. The positive expression of CD31 was visualized as brown-yellow or brown granules in the cytoplasm of the vascular endothelial cells. In the SHG44 tumors injected with the recombinant lentNT4/A1, the MVD was significantly reduced (lentNT4/Al + SHG44 vs. SHG44, $10.33 \pm 1.453$ vs. $25.33 \pm 2.028 ; \mathrm{P}<0.039$ ) (Fig. 4A). In U87 tumors injected with the recombinant lentNT4/A1, the MVD was also significantly reduced (lentNT4/Al + U87 vs. U87, $11.33 \pm 1.764$ vs. $27.64 \pm 1.475$; $\mathrm{P}<0.001$ ) (Fig. $4 \mathrm{~B}$ ). The results suggest that alphastatin significantly inhibits tumor angiogenesis, and that secreted protein alphastatin effectively suppresses tumor growth in an established tumor model, as a result of antiangiogenetic effects.

\section{Discussion}

Alphastatin is an endogenous angiogenesis inhibitor with potent antiangiogenic properties which inhibits both the migration and tube formation of human endothelial cells induced by VEGF or bFGF, and in tumor models by inhibiting tumor growth through suppressing angiogenesis. Using lentivirus-mediated gene transfer, we previously found that lentNT4/Al-infected HUVECs were able to stably secrete alphastatin, which exhibited a potent inhibitory effect on HUVEC migration and differentiation. We also explored the inhibitory effects of secreted protein alphastatin on tumorigenesis in glioma, in which secreted protein alphastatin significantly suppressed tumorigenesis, since the influence of alphastatin on the growth of glioma cells and the effects of alphastatin therapy on established tumors remain unclear. Here, we demonstrated in SHG44-Al and U87-Al cells and an established treatment model for human glioma that lentivirusmediated gene transfer of alphastatin is a potential therapeutic strategy against glioma and, alphastatin inhibits tumor growth by blocking VE-cadherin turnover.

Lentiviral vectors offer the advantage that they can integrate their cDNA into both dividing and nondividing cells (19). In addition, VSV-G pseudotyped lentiviral vectors, which can bind to cell surface phospholipids (20), have a potential advantage in achieving efficient gene delivery to endothelial cells. Furthermore, a third-generation SIN lentiviral vector, in which the U3 region of the 3' LTR (including the TATA box) was deleted, abolishing any LTR promoter activity (21), enhanced 

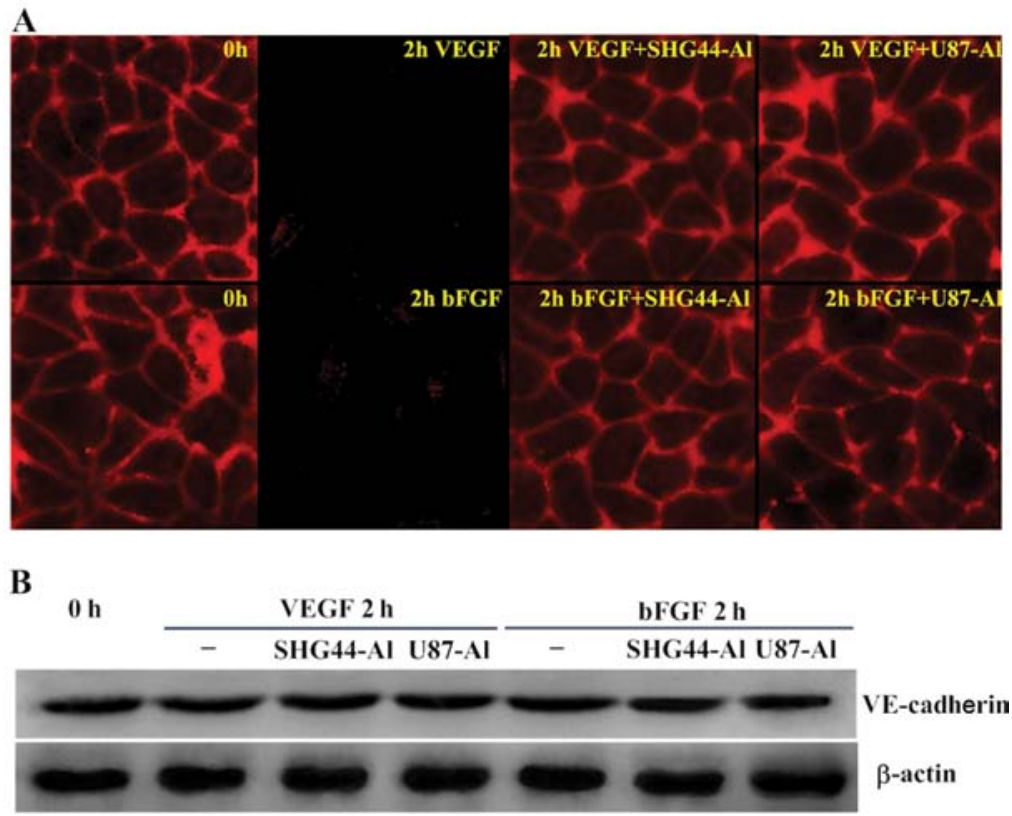

Figure 3. Effect of alphastatin on VE-cadherin. Adherence junction molecule VE-cadherin was detected during endothelial cell capillary tube formation induced by $10 \mathrm{ng} / \mathrm{ml}$ VEGF or bFGF at 0 and $2 \mathrm{~h}$, and treated with or without alphastatin conditioned medium. (A) Immunolocalization of VE-cadherin by immunofluorescence microscopy; magnification, $x$ 400. (B) VE-cadherin expression levels were analyzed by western blotting. $\beta$-actin was used as a loading control.

A
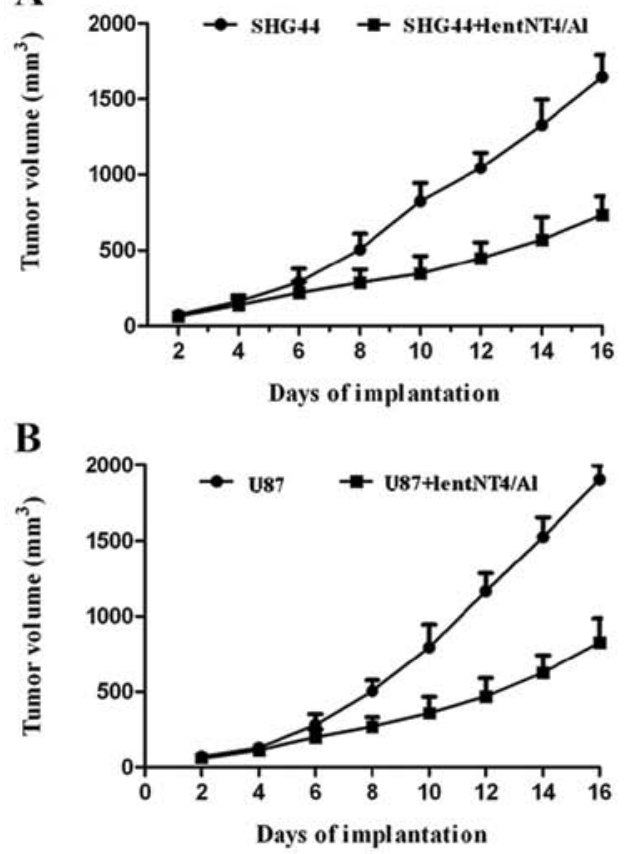
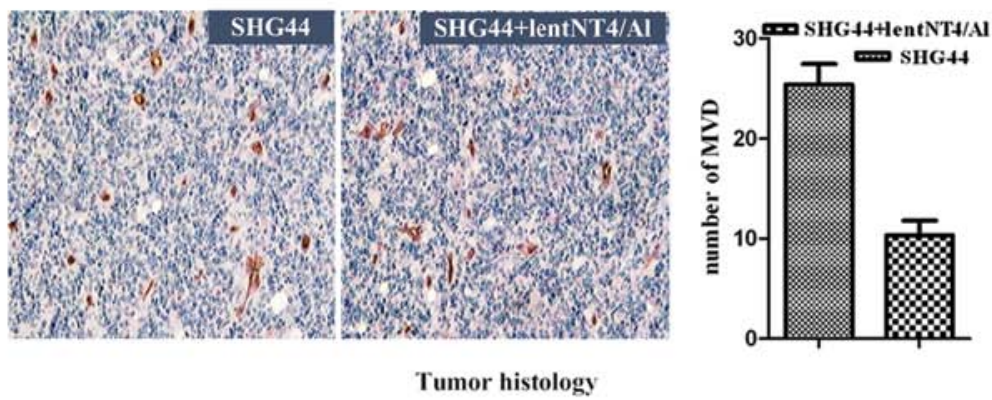

Tumor histology


Tumor histology

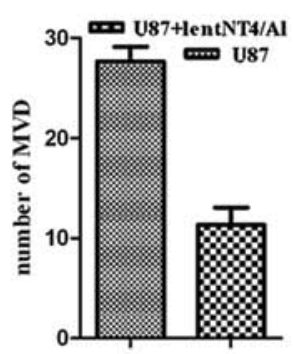

Figure 4. Effects of alphastatin on tumor growth and tumor histology. (A) The line graph shows the changes in SHG44 tumor volume over 16 days. Data are expressed as means \pm SEM. P<0.018, SHG44 + lentNT4/Al vs. SHG44. The MVD values are expressed as means \pm SEM. P<0.039; SHG44 + lentNT4/Al vs. SHG44 (original magnification, $x 20$ ). (B). The line graph shows the changes in U87 tumor volume over 16 days. Data are expressed as means \pm SEM. P $<0.022$; U87+ lentNT4/Al vs. U87. The MVD values are expressed as means \pm SEM. P<0.001; U87 + lentNT4/Al vs. U87 (original magnification, x20).

the security level of transgene expression. Accordingly, the NT4 signal peptide and pro-region sequence were fused in-frame to the 5 ' ends of each coding sequence to ensure exogenous protein expressing in a secretory manner (22-26), and the lentNT4/Al gene delivery system was constructed. Moreover, since previous results showed that secreted protein alphastatin had signifi- cantly attained a saturated concentration of antiangiogenesis in respective conditioned medium (11), there was no concern with variation of concentration of secreted protein in this study.

Since secreted protein alphastatin is sustainably expressed in HUVEC-Al cells, and in vitro and in glioma models significantly inhibit angiogenesis and gliomagenesis, we aimed to 
ascertain whether alphastatin also remains stably expressed in SHG44-Al and U87-Al cells. We investigated its anti-glioma activity involving its efficacy in the treatment of glioma, and the analysis of the treatment mechanism. In view of the successful construction of the lentiviral vector containing the NT4-alphastatin fusion gene and sustainable expression of alphastatin in HUVEC-Al cells, in this study, we constructed SHG-44-Al and U87-Al cells, and by morphological observation confirmed whether alphastatin was secreted in these cells. We showed that, in an endothelial migration assay, SHG-44-Al and U87-Al conditioned media had a similar inhibitory effect on endothelial cell migration, which suggested that alphastatin was successfully secreted in SHG-44-Al and U87-Al cells. Notably, although injection of the recombinant lentNT4/A1 significantly inhibited tumor growth, our data also showed that secreted protein alphastatin did not affect the proliferative ability and migration of glioma cells in vitro. This may be due to the fact that alphastatin acts only on endothelial cell angiogenesis, but not on glioma cells. Taken together, our data suggest that secreted protein alphastatin is stably expressed in SHG44-Al and U87-Al cells, leading to growth suppression of glioma by inhibition of endothelial cell migration and tube formation.

VE-cadherin is a major component of endothelial adherens junctions necessary for blood vessel integrity and endothelial cell survival $(27,28)$. VE-cadherin has emerged as an adhesion molecule that plays fundamental roles in microvascular permeability and in morphogenic and proliferative events associated with angiogenesis (29-31). Since blocking angiogenesis is a common strategy with which to inhibit tumor growth, several approaches to inhibiting VE-cadherin function have been suggested as possible antitumor therapies (32-35). Several studies have demonstrated that VE-cadherin turnover in endothelial cells suppresses angiogenesis (16,36-39), and is closely related to the MAPK pathways $(40,41)$. Our finding that alphastatin inhibits VE-cadherin downregulation induced by VEGF or bFGF on the surface membrane of HUVECs without any changes in total protein of VE-cadherin suggests that VEGF or bFGF induces VE-cadherin redistribution in endothelial cells, which is inhibited by alphastatin. Our previous data also indicate that secreted protein alphastatin inhibits VEGF- or bFGF-induced angiogenesis by suppressing the JNK and ERK kinase activation pathways in HUVECs. We previously confirmed that the antiangiogenetic activity of alphastatin most likely operates at a post-receptor locus common to the VEGF and bFGF signaling pathways (9). Thus, our data indicate that the antiangiogenesis mechanism of alphastatin, by blocking VEGF and bFGF post-receptor signaling pathways, suppresses JNK and ERK kinase activation, which lead to VE-cadherin turnover on the endothelial cell membrane, and then, inhibits endothelial cell migration and differentiation. Finally, alphastatin not only inhibits new vessel growth, but more important it significantly causes regression of existing tumor vessels.

In conclusion, in our study of antiangiogenesis of alphastatin, we describe the anti-glioma therapeutic strategy involving lentivirus-mediated gene transfer of alphastatin and its role in the inhibition of tumorigenesis. We have demonstrated that in vivo, a subcutaneous injection of recombined lentiNT4-Al resulted in the significantly growth inhibition of glioma in autocrine manner (HUVEC-Al cells) or in para- crine manner (in SHG-44-Al and U87-Al cells), and in vitro, offering a molecular explanation for the mechanism of the effect of alphastatin against glioma involving VE-cadherin. This study is the first report on an anti-glioma therapeutic strategy involving lentivirus-mediated gene transfer of alphastatin.

\section{Acknowledgements}

We thank Quan-Ying Wang, Guang-Xiao Yang (Xi'an Huaguang Bioengineering Co.) for their expert technical assistance concerning the construction of the recombined plasmid. We are also grateful to Dr Cunjie Li and Huishou Wang for their help during the experiments. This study was supported by the Postdoctoral Science Foundation of China (no. 201150M1522) and the National Natural Science Foundation of China (no. 30672162).

\section{References}

1. Tuettenberg J, Friedel C and Vajkoczy P: Angiogenesis in malignant glioma - a target for antitumor therapy? Crit Rev Oncol Hematol 59: 181-193, 2006.

2. Jain RK, di Tomaso E, Duda DG, Loeffler JS, Sorensen AG and Batchelor TT: Angiogenesis in brain tumours. Nat Rev Neurosci 8: 610-622, 2007.

3. Vajkoczy $P$ and Menger MD: Vascular microenvironment in gliomas. J Neurooncol 50: 99-108, 2000.

4. Norden AD, Young GS, Setayesh K, Muzikansky A, Klufas R, Ross GL, Ciampa AS, Ebbeling LG, Levy B, Drappatz J, Kesari S and Wen PY: Bevacizumab for recurrent malignant gliomas: efficacy, toxicity, and patterns of recurrence. Neurology 70: 779-787, 2008 .

5. Batchelor TT, Duda DG, di Tomaso E, Ancukiewicz M,Plotkin SR, Gerstner E, Eichler AF, Drappatz J, Hochberg FH, Benner T, Louis DN, Cohen KS, Chea H, Exarhopoulos A, Loeffler JS, Moses MA, Ivy P, Sorensen AG, Wen PY and Jain RK: Phase II study of cediranib, an oral pan-vascular endothelial growth factor receptor tyrosine kinase inhibitor, in patients with recurrent glioblastoma. J Clin Oncol 28: 2817-2823, 2010.

6. Nyberg P, Xie L and Kalluri R: Endogenous inhibitors of angiogenesis. Cancer Res 65: 3967-3979, 2005.

7. Folkman J: Endogenous angiogenesis inhibitors. APMIS 112: 496-507, 2004

8. Cao Y: Endogenous angiogenesis inhibitors and their therapeutic implications. Int J Biochem Cell Biol 33: 357-369, 2001.

9. Staton CA, Brown NJ, Rodgers GR, Corke KP, Tazzyman S, Underwood JC and Lewis CE: Alphastatin, a 24-amino acid fragment of human fibrinogen, is a potent new inhibitor of activated endothelial cells in vitro and in vivo. Blood 103: 601-606, 2004.

10. Li Y, Qiu S, Song L, Yan Q and Yang G: Secretory expression of p53(N15)-Ant following lentivirus-mediated gene transfer induces cell death in human cancer cells. Cancer Invest 26: 28-34, 2008.

11. Guo SW, Che HM and Li WZ: Anti-tumor effect of lentivirusmediated gene transfer of alphastatin on human glioma. Cancer Sci 102: 1038-1044, 2011.

12. Xiaojiang T, Jinsong Z, Jiansheng W, Chengen P, Guangxiao Y and Quanying W: Adeno-associated virus harboring fusion gene NT4-ant-shepherdin induces cell death in human lung cancer cells. Cancer Invest 28: 465-471, 2010.

13. Marr RA, Rockenstein E, Mukherjee A, Kindy MS, Hersh LB, Gage FH, Verma IM and Masliah E: Neprilysin gene transfer reduces human amyloid pathology in transgenic mice. J Neurosci 23: 1992-1996, 2003.

14. Malinda KM, Ponce L, Kleinman HK, Shackelton LM and Millis AJ: Gp38k, a protein synthesized by vascular smooth muscle cells, stimulates directional migration of human umbilical vein endothelial cells. Exp Cell Res 250: 168-173, 1999.

15. Liu J, Kolath J, Anderson J, Kolar C, Lawson TA, Talmadge J and Gmeiner WH: Positive interaction between 5-FU and FdUMP[10] in the inhibition of human colorectal tumor cell proliferation. Antisense Nucleic Acid Drug Dev 9: 481-486, 1999. 
16. Wright TJ, Leach L, Shaw PE and Jones P: Dynamics of vascular endothelial-cadherin and beta-catenin localization by vascular endothelial growth factor-induced angiogenesis in human umbilical vein cells. Exp Cell Res 280: 159-168, 2002.

17. Grosios K, Holwell SE, McGown AT, Pettit GR and Bibby MC: In vivo and in vitro evaluation of combretastatin A-4 and its sodium phosphate prodrug. Br J Cancer 81: 1318-1327, 1999.

18. Beckstead JH: A simple technique for preservation of fixationsensitive antigens in paraffin-embedded tissues. J Histochem Cytochem 42: 1127-1134, 1994.

19. Naldini L, Blömer U, Gallay P, Ory D, Mulligan R, Gage FH, Verma IM and Trono D: In vivo gene delivery and stable transduction of nondividing cells by a lentiviral vector. Science 272 263-267, 1996

20. Schlegel R, Tralka TS, Willingham MC and Pastan I: Inhibition of VSV binding and infectivity by phosphatidylserine: is phosphatidylserine a VSV-binding site? Cell 32: 639-646, 1983.

21. Zufferey R, Dull T, Mandel RJ, Bukovsky A, Quiroz D, Naldini L and Trono D: Self-inactivating lentivirus vector for safe and efficient in vivo gene delivery. J Virol 72: 9873-9880, 1998.

22. Nagai K, Oubridge C, Kuglstatter A, Menichelli E, Isel C and Jovine L: Structure, function and evolution of the signal recognition particle. EMBO J 22: 3479-3485, 2003.

23. Müller JP, Bron S, Venema G and van Dijl JM: Chaperone-like activities of the CsaA protein of Bacillus subtilis. Microbiology 146: 77-88, 2000.

24. Tjalsma H, Antelmann H, Jongbloed JD, Braun PG, Darmon E, Dorenbos R, Dubois JY, Westers H, Zanen G, Quax WJ, Kuipers OP, Bron S, Hecker M and van Dijl JM: Proteomics of protein secretion by Bacillus subtilis: separating the 'secrets' of the secretome. Microbiol Mol Biol Rev 68: 207-233, 2004.

25. Zanen G, Antelmann H, Meima R, Jongbloed JD, Kolkman M, Hecker M, van Dijl JM and Quax WJ: Proteomic dissection of potential signal recognition particle dependence in protein secretion by Bacillus subtilis. Proteomics 6: 3636-3648, 2006.

26. Fan G, Egles C, Sun Y, Minichiello L, Renger JJ, Klein R, Liu G and Jaenisch R: Knocking the NT4 gene into the BDNF locus rescues BDNF-deficient mice and reveals distinct NT4 and BDNF activities. Nat Neurosci 3: 350-357, 2000

27. Corada M, Mariotti M, Thurston G, Smith K, Kunkel R, Brockhaus M, Lampugnani MG, Martin-Padura I, Stoppacciaro A, Ruco L, McDonald DM, Ward PA and Dejana E: Vascular endothelial-cadherin is an important determinant of microvascular integrity in vivo. Proc Natl Acad Sci USA 96: 9815-9820, 1999.

28. Carmeliet P, Lampugnani MG, Moons L, Breviario F, Compernolle V, Bono F, Balconi G, Spagnuolo R, Oosthuyse B, Dewerchin M, Zanetti A, Angellilo A, Mattot V, Nuyens D, Lutgens E, Clotman F, de Ruiter MC, Gittenberger-de Groot A, Poelmann R, Lupu F, Herbert JM, Collen D and Dejana E: Targeted deficiency or cytosolic truncation of the VE-cadherin gene in mice impairs VEGF-mediated endothelial survival and angiogenesis. Cell 98: 147-157, 1999.

29. Dejana E, Bazzoni $G$ and Lampugnani MG: Vascular endothelial (VE)-cadherin: only an intercellular glue? Exp Cell Res 252. 13-19, 1999.
30. Dejana E, Spagnuolo R and Bazzoni G: Interendothelial junctions and their role in the control of angiogenesis, vascular permeability and leukocyte transmigration. Thromb Haemost 86: 308-315, 2001.

31. Stevens T, Garcia JG, Shasby DM, Bhattacharya J and Malik AB: Mechanisms regulating endothelial cell barrier function. Am J Physiol Lung Cell Mol Physiol 279: L419-L422, 2000.

32. Liao F, Li Y, O'Connor W, Zanetta L, Bassi R, Santiago A, Overholser J, Hooper A, Mignatti P, Dejana E, Hicklin DJ and Bohlen P: Monoclonal antibody to vascular endothelialcadherin is a potent inhibitor of angiogenesis, tumor growth, and metastasis. Cancer Res 60: 6805-6810, 2000.

33. Liao F, Doody JF, Overholser J, Finnerty B, Bassi R, Wu Y, Dejana E, Kussie P, Bohlen P and Hicklin DJ: Selective targeting of angiogenic tumor vasculature by vascular endothelialcadherin antibody inhibits tumor growth without affecting vascular permeability. Cancer Res 62: 2567-2575, 2002.

34. Corada M, Zanetta L, Orsenigo F, Breviario F, Lampugnani MG, Bernasconi S, Liao F, Hicklin DJ, Bohlen P and Dejana E: A monoclonal antibody to vascular endothelial-cadherin inhibits tumor angiogenesis without side effects on endothelial permeability. Blood 100: 905-911, 2002.

35. Pierce M, Wang C, Stump M and Kamb A: Overexpression of the beta-catenin binding domain of cadherin selectively kills colorectal cancer cells. Int J Cancer 107: 229-237, 2003.

36. Abraham S, Yeo M, Montero-Balaguer M, Paterson H, Dejana E, Marshall CJ and Mavria G: VE-Cadherin-mediated cell-cell interaction suppresses sprouting via signaling to MLC2 phosphorylation. Curr Biol 19: 668-674, 2009.

37. Hatanaka K, Simons M and Murakami M: Phosphorylation of VE-cadherin controls endothelial phenotypes via p120-catenin coupling and Racl activation. Am J Physiol Heart Circ Physiol 300: H162-H172, 2011.

38. Fukuhra S, Sakurai A, Yamagishi A, Sako K and Mochizuki N: Vascular endothelial cadherin-mediated cell-cell adhesion regulated by a small GTPase, Rap1. J Biochem Mol Biol 39: 132-139, 2006.

39. Xiao K, Garner J, Buckley KM, Vincent PA, Chiasson CM, Dejana E, Faundez V and Kowalczyk AP: p120-Catenin regulates clathrin-dependent endocytosis of VE-cadherin. Mol Biol Cell 16: 5141-5151, 2005

40. Wu JC, Yan HC, Chen WT, Chen WH, Wang CJ, Chi YC and Kao WY: JNK signaling pathway is required for bFGF-mediated surface cadherin downregulation on HUVEC. Exp Cell Res 314: 421-429, 2008

41. Grazia Lampugnani M, Zanetti A, Corada M, Takahashi T, Balconi G, Breviario F, Orsenigo F, Cattelino A, Kemler R, Daniel TO and Dejana E: Contact inhibition of VEGF-induced proliferation requires vascular endothelial cadherin, betacatenin, and the phosphatase DEP-1/CD148. J Cell Biol 161: 793-804, 2003 